\title{
Neurobiology and clinical features of impulse control failure in Parkinson's disease
}

\author{
Matthieu Béreau', Paul Krack ${ }^{2^{*}}$, Norbert Brüggemann ${ }^{3}$ and Thomas F. Münte ${ }^{3,4^{*}}$ [D
}

\begin{abstract}
Impulse control disorders (ICDs) and other impulsive-compulsive related behaviours are frequent and still under recognized non-motor complications of Parkinson's disease (PD). They result from sensitization of the mesocorticolimbic pathway that arose in predisposed PD patients concomitantly with spreading of PD pathology, non-physiological dopaminergic and pulsatile administration of dopamine replacement therapy (DRT).

Neuropsychiatric fluctuations (NPF) reflect the psychotropic effects of dopaminergic drugs and play a crucial role in the emergence of ICDs and behavioral addictions. Dopamine agonists (DA) which selectively target D2 and D3 receptors mostly expressed within the mesocorticolimbic pathway, are the main risk factor to develop ICDs. Neuroimaging studies suggest that dopamine agonists lead to a blunted response of the brain's reward system both during reward delivery and anticipation. Genetic predispositions are crucial for the responsiveness of the mesolimbic system and the development of ICDs with several genes having been identified. Early screening for neuropsychiatric fluctuations, reduction of DA, fractionating levodopa dosage, education of patients and their relatives, are the key strategies for diagnosis and management of ICDs and related disorders.
\end{abstract}

Keywords: Parkinson's disease, Impulse control disorders, Behavioral addictions, Dopamine, Neuropsychiatric fluctuations, Mesocorticolimbic sensitization

\section{Background}

Although motor signs namely bradykinesia, rigidity and tremor are still considered as the core feature of diagnostic criteria for Parkinson disease (PD) [71], increasing recognition has been given over time to non-motor manifestations of PD including cognitive, autonomic, and neuropsychiatric signs [99]. Neuropsychiatric signs refer first of all to anxiety, apathy and depression that are frequently encountered in de novo drug-naïve PD patients [54] and reverted when dopamine replacement therapy (DRT) is introduced [66, 81]. Neuropsychiatric signs also encompass neuropsychiatric fluctuations (NPF), Impulse control disorders (ICDs) and related disorders, and psychosis that are frequently observed along the progression of PD pathology and the concurrent pulsatile administration

\footnotetext{
*Correspondence: Paul.krack@insel.ch; Thomas.muente@neuro.uniluebeck.de

${ }^{2}$ Department of Neurology, Inselspital, University of Bern, $\mathrm{CH}-3010$ Bern, Switzerland

${ }^{3}$ Department of Neurology, University of Lübeck, 23562 Lübeck, Germany Full list of author information is available at the end of the article
}

of increasing doses of DRT $[25,46,52]$. Therefore, behavioural disorders in PD have been conceptualized as a hypodopaminergic behavioural syndrome where apathy predominates, hyperdopaminergic behavioural syndrome which includes ICDs and other behavioural addictions, and non-motor fluctuations $[2,75]$ that together, define two opposite sides of one behavioural spectrum [81]. ICDs and related behaviors comprise a set of behaviors characterized by both impulsive and compulsive aspects. Impulsive aspects refer to an inability to resist an impulse or inappropriate drive despite harmful consequences for patients and their relatives, whereas compulsive aspects refer to the intrinsic repetitive nature of these behaviors that indicate a lack of self-control [100]. As with drug addictions, ICDs and related disorders are underpinned by one common pathophysiological mechanism that consists in hypersensitization of reward circuits and heightened ventral striatal dopamine release in response to reward-related cues [52]. Thus, from a clinical perspective, pathological gambling has been removed from ICDs in DSM-IV 
diagnostic criteria to be included into behavioural addictions in DSM-V. However, DSM-V nosology of ICDs and related disorders remains unclear and shared between ICDs and behavioural addictions. Based on the pathophysiology of those disorders, we prefer the label of behavioural addictions to describe the full spectrum of hyperdopaminergic behaviours $[6,52]$. Dopamine dysregulation syndrome (DDS) is a specific entity characterized by compulsive use of levodopa irrespective of motor-fluctuations and dyskinesias, along with behavioural changes from the spectrum of behavioural addictions $[30,47]$. Although DDS was initially thought to be driven by the severity of non-motor OFF symptoms such as pain or anxiety, a recent study argued that the non-motor "ON-drug" state was the driving force that enhance compulsive drug intake [20]. Thus, patients who developed DDS might be seeking "ON-drug" euphoria rather than preventing "OFF-drug" dysphoria [20]. Behavioural addictions result from complex interaction between individual risk factors, PD pathology and DRT. The purpose of the present review is to delineate the neurobiology and the clinical spectrum of behavioural addictions that are still under recognized despite their potential devastating consequences for patients and their relatives [69].

\section{Neurobiology \\ Brain systems involved}

The mesolimbic dopaminergic system consisting of the dopaminergic ventral tegemental area (VTA) and the ventral striatum, with the nucleus accumbens as most prominent player, has been frequently dubbed as the brain's reward system [38]. This view, however, falls considerably short of the complexity of the brain areas involved in guiding goal directed behavior [34, 36]. For example, Kelley [40] has compiled a complex network of brain areas including the mesolimbic dopaminergic system from animal work on ingestive behavior. Interestingly, we have been able to detect most of these brain areas in a neuroimaging study involving a gambling task ([11]; Fig. 1a). Inspection of this network suggest that the prefrontal cortex might act as a control instance. Indeed, ICDs in PD and in other conditions might be conceptualized as resulting from an imbalance between the craving for a reward and the inability to suppress this behavior, whenever it might not be appropriate.

\section{Intertemporal choice task}

To assess the interplay of the brain areas depicted in Fig. 1 and their involvement in ICDs in PD, the intertemporal choice paradigm has been used which involves choices between two rewards available at different times. Usually, this is an immediately available smaller reward and a larger reward which can be obtained only after a delay. A multitude of studies in humans and animals suggests that future are discounted in a quasi-hyperbolic or hyperbolic fashion $[28,57]$, the latter of which can be captured by the following function:

$$
V=\frac{A}{1+k D}
$$

where $\mathrm{V}$ is the present value of the delayed reward $\mathrm{A}$ after a delay $\mathrm{D}$, and $\mathrm{k}$ is the delay discount rate. A greater delay discount rate indicates a steeper discount function, i.e. a more pronounced devaluation of future rewards. The neural underpinnings of intertemporal choice have been investigated using neuroimaging studies in humans and neurophysiological recordings in primates and other species [7, 23, 24, 35, 37, 55, 58, 59, 68, 109]. One of the earliest neuroimaging studies of intertemporal choice proposed two neural systems in intertemporal choice [58, 59]: a beta system, comprising limbic structures thought to place special weight on immediate rewards, whereas prefrontal cortical structures, the delta system, are thought to mediate deliberate, patient choices. Alternatively, a unitary system comprising medial prefrontal and posterior cingulate cortex and the ventral striatum has been proposed which represents and compares the values of both, immediate and delayed choices (Kable and Glimcher, 2007Peters and Büchel, 2009). Volkow and Baler [93] have recently pointed out that decisions for immediate or delayed rewards (in their words "now" or "later" processes) are differentially modulated by dopamine signals. Whereas decisions for delayed rewards require steady, tonic firing of dopaminergic neurons in striatal and prefrontal regions to sustain effort, "now" processes are thought to be dependent on fast, burst-like firing of dopaminergic neurons in ventral and dorsal striatal regions, which drives the desire to attain and consume the stimulus. This model is supported by brain imaging studies [27, 94].

Voon et al. [96] employed an intertemporal choice task in PD patients with ICDs, PD patients without clinically apparent ICDs and healthy controls. Patients were tested on and off dopamine replacement therapy. Of note, the task used by Voon et al. [96] employed rather delays (7$28 \mathrm{~s}$ ) and real-time consummatory feedback during the task rather than long delays of weeks and months used in most behavioral economics tasks [41]. A group by medication interaction effect was revealed, reflecting a steeper discounting curve (i.e. more impulsive choice) in PD patients with ICDs when on dopamine agonist therapy. No medication effect was found in PD patients without ICDs. By contrast, Milenkova et al. [60] found a steeper discounting for PD patients in a monetary intertemporal choice task employing delays of up to 6 months. The PD patients in that study were not having clinically apparent ICDs. In a small study of 7 


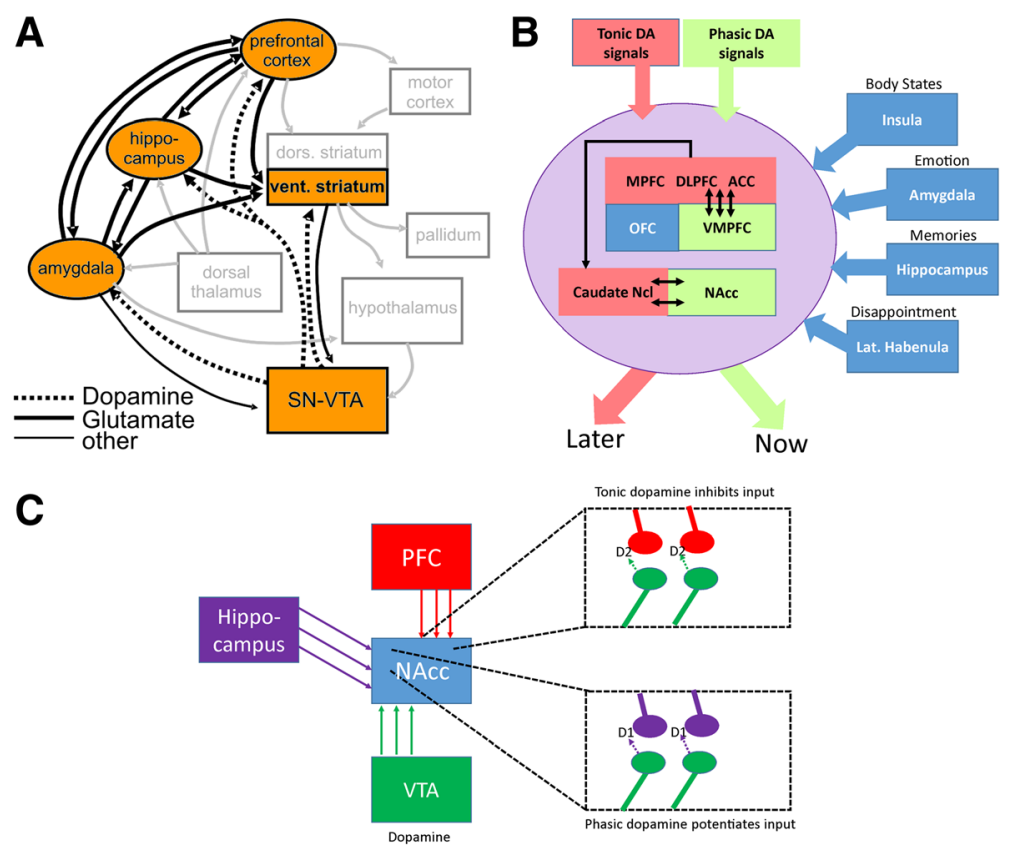

Fig. 1 a Scheme of the reward valuation network as derived from a neuroimaging study by Camara et al. [1 1] (orange boxes, black arrows) embedded in a wider motivation/learning circuit (gray boxes and arrows). The wider network is based on Kelley et al. (2004), omitting unspecific hypothalamic/thalamic projections. b Model of intertemporal choice behavior as proposed by Volkow and Baler [93]. The regions colored in red are considered to support decisions for later, larger rewards ("LATER"), whereas the green areas support decisions for immediately available rewards ("NOW"). Regions depicted in blue modulate intertemporal choice behavior by integrating different information (described in black lettering). Please note, that tonic dopamine (DA) signals are thought to favor LATER rewards by influencing frontal regions. By contrast, phasic DA signals drive decisions towards choosing the immediately available reward (NOW). Regions: dorsolateral prefrontal cortex (dIPFC), medial PFC (mPFC), ventromedial PFC (vmPFC), orbitofrontal cortex (OFC), anterior cingulate cortex (ACC), nucleus accumbens (NAcc). c lllustration of the role of phasic and tonic dopaminergic projections (after [32]): The Nacc serves as an integrator of afferent inputs from frontal and limbic regions. Of note, the input from the PFC is regulated by dopaminergic input from VTA via presynaptic D2 receptors, with D2 receptor stimulation resulting in an inhibition of PFC input to the Nacc. The presynaptic neurons are stimulated by tonic dopamine neuron firing leading to low tonic levels of dopamine. High-amplitude, phasic dopamine signals on the other hand lead to D1 receptor activation that potentiates the hippocampal input to the NAcc

presymptomatic carriers of duplications of the SNCA gene who later developed PD, Szamosi et al. [85] found a similar delay discounting behavior during the presymptomatic stage in carriers compared to non-carrier control participants. After the development of PD a significantly steeper discounting (i.e., more impulsive decisions) were seen in the subjects with SNCA duplications after the initiation of dopamine replacement therapy. Again, these patients did not exhibit overt ICDs. It thus appears that impulsive choices are more abundant even in PD patients without ICDs.

\section{Dopamine agonists lead to a blunted response of the reward system}

Clinical experience and large epidemiological studies (e.g., [102]) point to dopamine agonists as predisposing factors for the development of ICDs in PD. The question arises, how these drugs may modulate responses of the reward system. Importantly, Schott et al. [79] could demonstrate that reward-related ventral striatal dopamine release predicted functional magnetic resonance imaging activations in the ventral striatum during reward anticipation. Knutson and Gibbs [42] suggested that dopamine released in the Ncl. Accumbens (NAcc) changes the postsynaptic membrane potential by activating dopamine D1 receptors which in turn increases the local blood oxygen level dependent (BOLD) signal detected by fMRI. Thus, NAcc activity in response to possible rewards may be regulated by dopamine autoreceptors D2 and D3, which inhibit dopamine synthesis and/or release [22]. Dopamine D2/D3 receptor agonists then decrease NAcc dopamine release and reduce the incentive effect of rewards. Consistent with these predictions, we could demonstrate a blunted response to reward delivery in a gambling task in normal participants after a single dose of pramipexole ([74], Fig. 2a). Also, activation of the ventral striatum / NAcc was found reduced during anticipation of a reward in a monetary incentive delay task [106]. In Parkinson's disease, 
A Ventral Striatum Midbrain
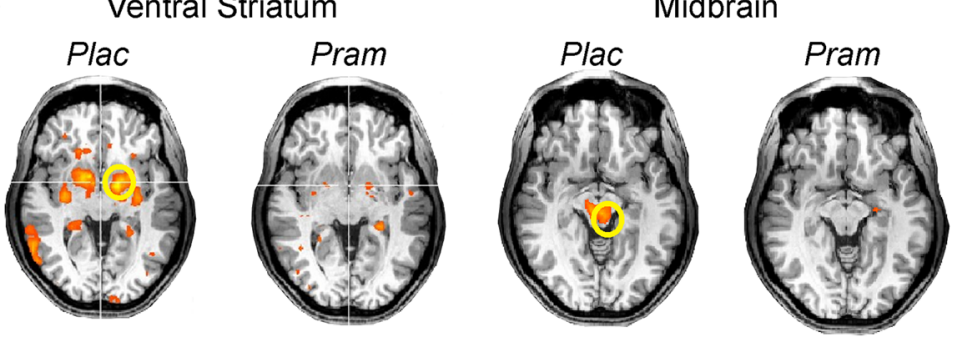

B

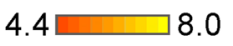

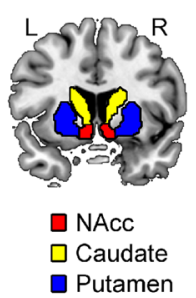

C

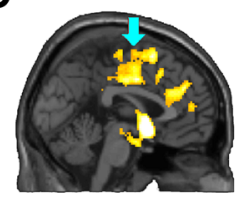

Placcebo

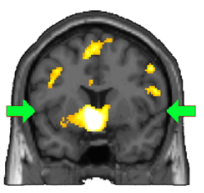

$\mathrm{HC}$

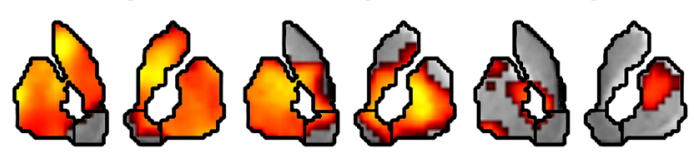

5

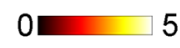

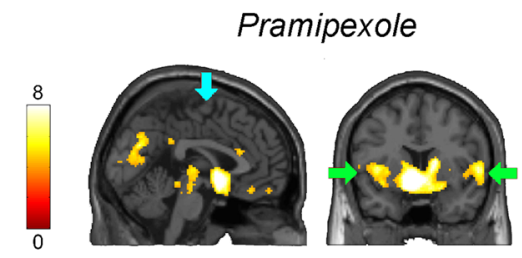
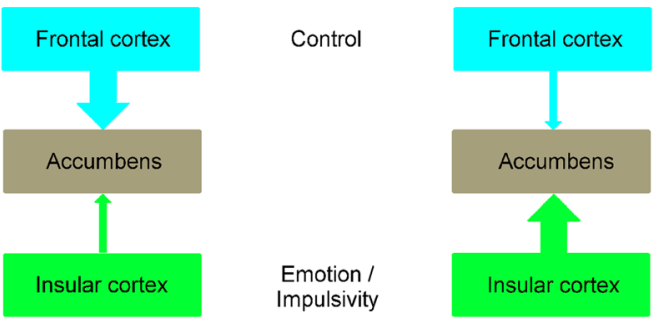

Fig. 2 a FMRI results from a gambling task in young healthy participants. Axial slices show greater activation for win compared to loss trials in the ventral striatum and midbrain after placebo and pramipexole. A single dose of pramipexole $(0.5 \mathrm{mg})$ resulted in a marked attenuation of reward based activations. After data presented in Riba et al. [74]. b FMRI results from a monetary incentive delay task. Shown are core regions of the reward processing network for the contrast "expectation of reward > expectation of no-reward". Please note that PD patients on dopamine agonist treatment show a marked attenuation of activation compared to healthy controls and PD patients off medication (unpublished data from Ye and Münte obtained from 17 PD patients and 17 matched control participants). c Nucleus accumbens connectivity during reward expectation in a monetary incentive delay task. Regions functionally connected with the NAcc during reward expectation under placebo and pramipexole. Arrows indicate the frontal cortex (blue) and the insular cortex (green). The scheme at the bottom presents the connectivity patterns under placebo and pramipexole. The dopamine agonist therapy results in a shift of connectivity (less connectivity between NAcc and frontal cortex, greater connectivity between NAcc and insular cortex)

fMRI activations to anticipated rewards were reduced in patients on dopaminergic agonist therapy but not patients off therapy (Fig. 2b). In addition to changing the response in the NAcc, dopaminergic agonist therapy also leads to profound changes of connectivity: Connections between the dorsolateral prefrontal cortex and the NAcc are downregulated after pramipexole, whereas connections between the insula and the NAcc are upregulated ([11]; Fig. 2c). Van Eimeren et al. [91] used $\mathrm{H}_{2}{ }^{15} \mathrm{O}$ PET before and after administration of $3 \mathrm{mg}$ apomorphine to assess regional cerebral blood flow during a gambling task in PD patients with pathological gambling and PD patients without ICDs. Indeed, gamblers showed a significant DA-induced reduction of activity in reward related brain areas, corroborating the previously mentioned results. PD patients with ICDs have also been studied using radioligands binding to dopamine receptors. For example, Stark et al. [84] used $\left[{ }^{18} \mathrm{~F}\right]$ fallypride, a 
high affinity D2-like receptor ligand in PD patients with and without ICDs. Patients with ICD had reduced binding potential in the ventral striatum and ICD symptoms positively correlated with midbrain D2/3 receptor binding potential. The authors suggested that ICDs in PD are associated with reduced ventral and dorsal striatal D2/3 expression, which may account for their differential response to dopamine agonist therapy.

\section{Genetics}

As not all PD patients on DRT develop behavioral addictions / ICD, the question arises whether a specific genetic background disposition might contribute to such behaviors. Multiple studies have been conducted to pinpoint single nucleotide polymorphisms (SNPs), mostly in genes related to the function of monaminergic transmitter systems, as either conducive or protecting. Evidence suggests a role of SNPs in genes involved in dopamine metabolism (COMT, DAT), dopamine receptors (DRD1, DRD2, DRD3, DRD4), serotonin receptors (HTR2A) and transporters (5HTT), and glutamate receptors (GRIN2B) [48, 49, 108], even though some studies also were negative [90]. These studies suggest that genetical factors play an important role in behavioral addictions in PD. However, as in other cognitive domains (e.g., executive functions, [45]) each SNP may account only for a small portion of the variance.

Therefore, a recent prospective multigene study by Kraemmer et al. [44] is of utmost importance. In this study, de novo drug-naïve patients $(n=276)$ with PD who had no behavioral addictions / ICD at the initial measurement were followed for 3 years. During this period 238 patients started DRT of whom $40 \%$ were taking a DA. During the follow-up, 19\% of the patients developed behavioral addictions / ICD as determined by the Questionnaire for Impulsive-Compulsive Disorders in PD (QUIP). Heritability of such behaviors was estimated to be $57 \%$ by restricted maximum likelihood analysis on whole exome sequencing data. Importantly, the occurrence of behavioral addiction in a given patient could be predicted with $87 \%$ accuracy in patients receiving DA when a model contained clinical data and the genotypes of 13 candidate variants in the DRD2, DRD3, DAT1, COMT, DDC, GRIN2B, ADRA2C, SERT, TPH2, HTR2A, OPRK1 and OPRM1 genes. This compared to $71 \%$ accuracy based on clinical data alone. A backward stepwise regression analysis identified age, male sex, dopamine replacement therapy and ADRA2C, DRD2, DDC, HTR2A and OPRK1 genotypes as significant predictors of behavioral addiction / impulse control disorders. Taken together, this suggests that it might be possible in the future to predict which patients are vulnerable to behavioral addictions prior to initiation of DA therapy.

\section{Beyond the dopaminergic system}

A number of animal studies $[4,21]$ as well as work in human PD patients [31, 92, 98] have suggested a role for noradrenaline in impulsivity and inhibitory functions in addition to the undisputed function of the dopaminergic system. These findings have triggered studies using the selective noradrenaline reuptake inhibitor atomoxetine in PD to modulate the response inhibition system [10, 39, 73, 105, 107]. For example, Ye et al. [105] employed the stop-signal task in PD patients and control participants and found that the former had longer stop-signal reaction times as well as less stop-related activation in the right inferior frontal gyrus in fMRI accompanied by weaker functional connectivity between this region and the striatum. These changes in PD were normalized by atomoxetine. Rae et al. [73] using the same task proposed that atomoxetine acts by increasing sensitivity of the inferior frontal gyrus to afferent inputs from the pre-supplementary motor cortex. Warner et al. [98] reviewed the evidence for an effect of atomoxetine in clinical symptoms of impulsivity, risk taking, and global cognition. The few available studies indeed suggest a beneficial effect.

\section{Clinical features \\ Epidemiology}

Prevalence of ICDs and related behaviors ranged from 13,6 to $33 \%$ according to studies $[1,5,95,97,102]$. This variability is partly related to declarative and cultural bias, clinical scales applied to asses ICDs, as well as methodological issue: cross sectional versus prospective studies, the clinical spectrum considered (i.e. the four ICDs strictly speaking or the whole hyperdopaminergic behavioral spectrum) and differences in populations investigated (de novo $\mathrm{PD}$, surgical candidates or advanced PD). All together, these studies pointed out the close interaction between individual susceptibility, DRT and PD pathology in the emergence of behavioral addictions. Patients with ICBs and related behaviors were more likely to have anxious mood phenotype, more motor fluctuations, and to be younger [95, 97, 102]. Those results have been confirmed by the prospective ICARUS study where ICD positive patients were more likely to be male, younger at PD onset, have a longer disease duration, depressive symptoms and poorer quality of life [1].

As mentioned above, some recent genetic studies argued for a genetically determined risk factors for developing ICDs [17]. Polymorphisms in genes coding for dopamine metabolism, serotonine and glutamate receptors have been particularly studied [17]. Moreover, a large prospective study based on a candidate gene multivariable panel identified OPRK1 (involved in the opioid system) and DDC (dopamine system) polymorphisms as risk factors for ICDs and related disorders [44]. 
Dopamine agonist (DAs) exposure is the main risk factor of developing ICDs [100]. Since the DOMINION study, a drug class relationship has been postulated as DAs was associated with 2 to 3,5-fold increased odds of having an ICDs [102]. Those results were confirmed by further prospective studies $[5,18]$. Recently, a longitudinal study conducted in 411 patients showed that lifetime average daily dose and duration of treatment were independently associated with ICDs with significant dose-effect relationships [18]. DA that exhibit a higher selectivity for D2/3 receptors mainly expressed within the mesocorticolimbic pathway, play a crucial role in the emergence of behavioral addictions [33, 81]. Furthermore, the pulsatility of DRT involved in sensitization of D1 receptors within the nigrostriatal pathway and dyskinesias [70], may be implicated as well in sensitization of D3 receptors within the mesocorticolimbic pathway and behavioral addictions [20, 77, 81]. Short acting, high potency DAs but also levodopa are associated with punding and DDS [26, 47].

A case-control study comparing de novo untreated PD patients and unmatched healthy controls investigated the question whether PD itself could confer an altered risk for ICDs and related behaviours [104]. No significant difference between the two groups has been shown regarding the prevalence of any ICDs valued at about $20 \%$. The conclusion of this study was that PD alone, did not seem to provide an increased risk of developing ICDs [104]. However, once treatment is started, PD patients who have a more severe dopaminergic denervation as shown by DAT-scan are at higher risk to develop ICD. Thus, interaction between PD pathology and dopamine replacement therapy play a crucial role in the development of ICDs [82].

Behavioral addictions are more frequent in advanced PD and surgical DBS candidates [8, 25, 52]. Interestingly, advanced PD and surgical DBS candidates had higher disease duration, higher levodopa and agonist equivalent daily dose, and higher proportion of motor and non-motor fluctuations $[8,25,52]$. Moreover, multiple behavioral addictions have been frequently reported [25]. In the ALTHEA study, behavioral addictions were observed in $55 \%$ of PD patients with dyskinesias and motor complications [8]. Furthermore, frequency of ICDs symptoms was much higher in patients with severe dyskinesias compared to patients with mild to moderate dyskinesias. Dyskinesias occur in patients with high L-dopa sensitivity and result from a treatment, that is too pulsatile. Indeed, fractionating L-dopa or administering L-dopa with continuous perfusion can reverse dyskinesias and ICD [14]. Taken together, these observations support that pulsatility of DRT is another important common risk factor for both dyskinesia and ICD [8].
Neuropsychiatric fluctuations (NPF), that reflect mesocorticolimbic denervation along the progression of $\mathrm{PD}$ pathology, are associated with the emergence of behavioral addictions such as DDS in surgical DBS candidates [20], as well as post-operative withdrawal syndrome in post-operative DBS patients [86]. These results support a more complex interaction between DRT and PD pathology in the emergence of behavioral addictions. While non-motor fluctuations and ICDs are markedly reduced during the post-operative state in DBS PD patients [52, 53], DBS PD patients frequently develop post-operative apathy unmasked by the decrease in DRT, and related to desensitization of a more severe denervated dopaminergic and serotonergic mesocorticolimbic pathways [54, 86]. Thus, apathy and behavioral addictions may be considered as the Yin and Yang of dopamine dependent behaviors [81].

\section{Clinical spectrum}

The whole behavioral clinical spectrum illustrates the relation between personality, dopamine and behaviors [19, 51]. While PD patients frequently exhibit harm avoidance and introspective traits that refers to baseline personality traits [88], they also frequently develop apathy, anhedonia, depression, and anxiety during the premotor stage of the disease, the so-called "hypodopaminergic behavioural spectrum" [66, 80]. Conversely, later in the disease course, patients which are prone to develop ICDs and related disorders, the so-called "hyperdopaminergic behavioural spectrum", frequently exhibit novelty seeking, and risk-taking personality traits, the exact opposite of the premorbid pattern mentioned above $[19,51]$.

The "honey moon" defines a well-being state for patients, where motor and non-motor signs are reverted by DRT [2]. The psychotropic effect of dopaminergic drugs might be the main factor that reflects this well-being feeling expressed by patients. During the motor and non-motor fluctuations state, neuropsychiatric fluctuations (NPF) are characterized by dysphoria, sadness, indifference, vulnerability in OFF state, and euphoria, pleasure, self-confidence in ON state [56]. NPF might play the driving force that promote behavioral addictions [20].

The hyperdopaminergic spectrum encompasses the four ICDs originally described, namely pathological gambling, hypersexuality, compulsive buying and compulsive eating as well as other behavioral addictions such as hobbyism, punding, walkabouts, hoarding, and DDS [100]. Pathological gambling predominates in men and is characterized by a preference for casinos and slots machine that can lead to financial problems. PD patients with hypersexuality had increased libido, increased desire for frequent sexual intercourse, as well as compulsive use of sex lines telephone, internet pornography, or 
prostitution services [30,62]. Changes in sexual preferences and paraphilia have been more rarely reported [83]. Compulsive buying usually affects women and consists in an irrepressible and repetitive impulse to buy unnecessary items $[16,43]$. Compulsive eating is defined by a persistent binge eating that occurs during day or night, with excessive and uncontrollable consumption of food [63]. Hobbyism that recently arose among the hyperdopaminergic behavioral spectrum is characterized by perpetual repetitive actions such as reading, internet browsing, working on projects, or painting [100]. Some other patients may also exacerbate or develop a creative art work [50]. Hoarding refers to a compulsive collecting of objects without objective value. In such cases, it can lead to unsanitary living conditions [64]. Punding is characterized by stereotypical motor behaviors such as manipulations, examinations, collecting, and other purposeless repetitive actions, that are frequently accompanied by dyskinesias and dopamine dysregulation syndrome (DDS), suggesting a common pathophysiological mechanism [26]. DDS is a clinical entity that correspond to an addiction to DRT combined with mood fluctuations and other behavioral addictions [30, 47]. Addiction to dopamine medications manifested by a compulsive craving and self-medication with increasingly dose of dopamine irrespective of motor state and dyskinesias [30, 47]. This DRT addiction, can lead to the full-blown DDS, where mood fluctuations and other behavioral addictions such as punding are present $[30,47]$.

\section{Clinical tools}

Different clinical tools have been validated for screening and/or diagnosis of ICDs and related behaviors. The Minnesota Impulsive Disorders Interview (MIDI) one of the first scale reported is not specifically addressed to PD patients $[15,16]$. Other scales dedicated to PD have been developed: The Questionnaire for Impulsive Compulsive Disorders in Parkinson's disease (QUIP) for screening [101] and the rating scale version of the QUIP, namely the QUIP-RS [103]. The Ardouin scale for behavioral assessment is based on a semi-structured interview that encompasses the whole spectrum of behavioral spectrum from hypo- to hyperdopaminergic syndromes as well as non-motor fluctuations [2, 75]. Non-motor fluctuations can be specifically addressed and quantified with the Neuropsychiatric Fluctuations Scale (NFS), a recently developed tool [78].

\section{Management of ICDs}

Management of ICDs and related disorders remains challenging. Careful interview and education of patients and their relatives about risk factors: non-motor $\mathrm{ON}$ [20], dyskinesia [95, 97], DA intake (5 years cumulative risk of 50\%) [18] is a crucial step before starting DRT
[6]. Detection and evaluation of early changes in behaviors is mandatory when DRT is started. This consists of screening for benign changes along the behavioral spectrum from hypodopaminergia to hyperdopaminergia as well as neuropsychiatric fluctuations, using dedicated clinical scales [6].

When ICDs occur, practical management will be adapted, taking into account severity of ICDs and impact on QOL, rather than the semiology itself. Basically, DA dose reduction, fractionation of L-Dopa must be first considered. Importantly, clinicians have to bear in mind that desensitization of the mesolimbic dopaminergic system is prolonged and may take weeks or months $[12,13,52,86]$. In such cases, adjunction of clozapine, amantadine or naltrexone may be helpful. Moreover, in cases of ICDs associated with DDS and severe motor fluctuations in younger PD patients, STN-DBS may represent an interesting therapeutic option.

DA should be carefully tapered below the individual threshold of inducing behavioral addictions, while avoiding the appearance of dopamine withdrawal syndrome [72]. Continuous delivery of D2/D3 agonists using extended release formulations or transdermal administration should be preferred [29], but overall all available dopamine agonists are very similar in effect. Apomorphine is the only available exception, as this agonist has a D1/D2 profile similar to endogenous dopamine with effects similar to L-dopa. Constant delivery of apomorphine with subcutaneous infusion using a mini-pump is a good alternative [3, 89]. Although typically not mentioned in the literature as evidence based studies are lacking, L-Dopa fractionation that is indicated when motor complications and dyskinesia occur, should also be considered for the management of non-motor complications and behavioral addictions as the first approach in patients on L-dopa. Although studies are lacking, based on expertise this is the easiest and most effective approach. Efficacy of non-pulsatile administration of L-dopa has been shown in a prospective observational study of 66 consecutive PD patients treated with levodopa-carbidopa intestinal gel infusion. Catalan et al. [14] found a significant $64,4 \%$ reduction of ICDs symptoms compared to baseline over the 6-month's follow-up.

Clozapine, an atypical neuroleptic that improve levodopa induced psychosis and dyskinesia, has been reported to reduce ICDs symptoms in patients in which dopamine dose reduction did not improve those symptoms $[9,76]$. Conflicting results have been shown with amantadine, a glutamate receptor antagonist. Although one small double blind crossover study reported improvement in pathological gambling in PD patients [87], the DOMINION study highlighted a positive correlation between amantadine and ICDs, even when taking into account levodopa and DA dosages [102]. One small 
intervention study with the opioid antagonist naltrexone showed some evidence for an effect [67]. This effect was corroborated by small clinical trials in other, non-PD-related behavioral addictions [61]. Accordingly, additional data are needed to support the use of clozapine, amantadine or naltrexone for the treatment of ICDs and related disorders. STN-DBS is a well-established treatment for PD patients with motor complications. Moreover, drastic dopamine dose reduction following STN-DBS is responsible for substantial decrease of dyskinesia. Recently, a randomized controlled study comparing STN DBS plus medical therapy and best medical treatment over a period of 2 years, demonstrated a better behavioral outcome with STN DBS plus medical therapy compared to best medical treatment [53]. Finally, the potential usefulness of cognitive behavioral therapy (CBT) for ICDs and related disorders has been highlighted in one randomized study [65].

\section{Discussion and outlook}

Behavioral addictions / ICDs present a major problem in the clinical management of PD. Research over the past 20 years has revealed that occurrence of such behaviors is by no means an exceptional event [102] and that ICDs are but one aspect of a larger spectrum of hyperdopaminergic behavioral disorders that also include punding and dopamine dysregulation syndrome [6, 30, 47, 52]. Both dopamine agonists with a high affinity for the mesolimbic D3 receptor and pulsatile treatment with L-dopa contribute to ICD in interaction with the severity of the disease explaining that ICD can appear after many years of treatment and increase in DRT is not a mandatory prerequisite. Clinicians have to screen systematically for behavioral side effects of dopaminergic treatment using specific tools from initiation of therapy to the most advanced stages.

Neuroimaging approaches have only begun to unravel the neural underpinnings of these behaviors. A blunted response of the reward system comprising the ventral striatum as a core structure and a changed connectivity pattern are induced by dopamine agonists $[11,74,106]$. This shifts the balance towards more impulsive, risk seeking behaviors as evidenced by steeper discounting of future rewards seen most prominently in PD patients with ICDs [96]. A shift from the LATER system (in the sense of [93]) driven by tonic dopamine signals to the NOW system supported by phasic dopaminergic transmission underlies this preference for more impulsive behavior. These findings might be instrumental in the development of therapy strategies. Moreover, the finding of a substantial genetic contribution, i.e. predisposition, to the development of ICDs [44] might allow to taylor the dopamine replacement therapy according to the individual genetic profile.

\begin{abstract}
Abbreviations
DA: Dopamine agonists; DBS: Deep Brain Stimulation; DDS: Dopamine dysregulation syndrome; fMRl: functional magnetic resonance imaging; ICDs: Impulse control disorders; MIDI: Minnesota Impulsive Disorders Interview; NFS: Neuropsychiatric Fluctuations Scale; NPF: Neuropsychiatric fluctuations; PD: Parkinson's disease; PET: Positron emission tomography; QUIP: Questionnaire for Impulsive Compulsive Disorders in Parkinson's disease; QUIP-RS: Questionnaire for Impulsive Compulsive Disorders in Parkinson's disease Rating Scale
\end{abstract}

\section{Acknowledgements}

We thank our co-workers for their valuable contribution to our research.

Funding

TFM was supported by the DFG (SFB TR134 C1; GRK 1957). NB was supported by the DFG (GRK 1957).

\section{Availability of data and materials}

Not applicable, as this is a review article.

\section{Authors' contributions}

All authors co-wrote the article together. All authors read and approved the final manuscript.

Ethics approval and consent to participate

Not applicable, as this is a review article without original data.

Consent for publication

Not applicable.

\section{Competing interests}

Authors MB, NB and TFM declare no competing interests. PK received grants and personal fees from Medtronic, Boston Scientific, UCB, grants from St Jude Medical France, Edmond J \& Lily Safra Foundation, French Ministry of Health (PHRC), INSERM (French National Institute of Health and Research in Medicine), France Parkinson, Swiss National Science Foundation, ROGER DE SPOELBERCH Foundation, Centre National Recherche Scientifique, Orkyn, Homeperf, Bertarelli Foundation, outside the submitted work.

\section{Publisher's Note}

Springer Nature remains neutral with regard to jurisdictional claims in published maps and institutional affiliations.

\section{Author details}

${ }^{1}$ Department of Neurology, University Hospital of Besançon, 25030 Besançon, Cedex, France. '2Department of Neurology, Inselspital, University of Bern, CH-3010 Bern, Switzerland. 'Department of Neurology, University of Lübeck, 23562 Lübeck, Germany. ${ }^{4}$ Institute of Psychology II, University of Lübeck, 23562 Lübeck, Germany.

Received: 7 January 2019 Accepted: 12 February 2019

Published online: 20 March 2019

\section{References}

1. Antonini, A., Barone, P., Bonuccelli, U., Annoni, K., Asgharnejad, M., \& Stanzione, P. (2017). ICARUS study: Prevalence and clinical features of impulse control disorders in Parkinson's disease. Journal of Neurology, Neurosurgery and Psychiatry. https://doi.org/10.1136/jnnp-2016-315277.

2. Ardouin, C., Chéreau, I., Llorca, P. M., Lhommée, E., Durif, F., Pollak, P., \& Krack, P. (2009). Évaluation des troubles comportementaux hyper- et hypodopaminergiques dans la maladie de Parkinson. Revue Neurologique, 165(11), 845-856 https://doi.org/10.1016/j.neurol.2009.06.003.

3. Barbosa, P., Lees, A. J., Magee, C., Djamshidian, A., \& Warner, T. T. (2016). A retrospective evaluation of the frequency of impulsive compulsive behaviors in Parkinson's disease patients treated with continuous waking day apomorphine pumps. Mov Disord Clin Pract, 4(3), 323-328.

4. Bari, A., \& Robbins, T. W. (2013). Noradrenergic versus dopaminergic modulation of impulsivity, attention and monitoring behaviour in rats performing the stopsignal task: Possible relevance to ADHD. Psychopharmacology, 230, 89-111.

5. Bastiaens, J., Dorfman, B. J., Christos, P. J., \& Nirenberg, M. J. (2013). Prospective cohort study of impulse control disorders in Parkinson's disease. Movement Disorders, 28(3), 327-333 https://doi.org/10.1002/mds.25291. 
6. Béreau, M., Fleury, V., Bouthour, W., Castrioto, A., Lhommée, E., \& Krack, P. (2018). Hyperdopaminergic behavioral spectrum in Parkinson's disease: A review. Revue Neurologique, 1-11 https://doi.org/10.1016/j.neurol.2018.07.005.

7. Bickel, W. K., Pitcock, J. A., Yi, R., \& Angtuaco, E. J. C. (2009). Congruence of BOLD response across intertemporal choice conditions: Fictive and real money gains and losses. Journal of Neuroscience, 29, 8839-8846.

8. Biundo, R., Weis, L., Abbruzzese, G., Calandra-Buonaura, G., Cortelli, P., Jori, M. C., et al. (2017). Impulse control disorders in advanced Parkinson's disease with dyskinesia: The ALTHEA study. Movement Disorders, 32(11), 1557-1565.

9. Bonfils, N. A., Benyamina, A., Aubin, H. J., \& Luquiens, A. (2015). Clzapine use for refractory impulse control disorders in Parkinson's disease : a case report. Psychopharmacology, 232(19), 3677-3679.

10. Borchert, R. J., Rittman, T., Passamonti, L., Ye, Z., Sami, S., Jones, S. P., Nombela, C., Vázquez Rodríguez, P., Vatansever, D., Rae, C. L., Hughes, L. E., Robbins, T. W., \& Rowe, J. B. (2016). Atomoxetine enhances connectivity of prefrontal networks in Parkinson's disease. Neuropsychopharmacology, 41, 2171-2177.

11. Camara, E., Rodriguez-Fornells, A., Ye, Z., \& Münte, T. F. (2009). Reward networks in the brain as captured by connectivity measures. Frontiers in Neuroscience, 3, 350-362.

12. Castrioto, A., Carnicella, S., Fraix, V., Chabardes, S., Moro, E., \& Krack, P. (2017). Reversing dopaminergic sensitization. Movement Disorders, 32(12), 16791683 https://doi.org/10.1002/mds.27213

13. Castrioto, A., Kistner, A., Klinger, H., Lhommée, E., Schmitt, E., Fraix, V., et al. (2013). Psychostimulant effect of levodopa: Reversing sensitisation is possible. Journal of Neurology, Neurosurgery and Psychiatry, 84(1), 18-22 https://doi.org/10.1136/jnnp-2012-302444.

14. Catalan, M. J., Molina-Arjona, J. A., Mir, P., Cubo, E., Arbelo, J. M., MartinezMartin, P., \& EDIS Study Group. (2018). Improvement of impulse control disorders associated with levodopa-carbidopa intestinal gel treatment in advanced Parkinson's disease. Journal of Neurology, 265(6), 1279-1287.

15. Chamberlain, S. R., \& Grant, J. E. (2018). Minnesota impulse disorders interview (MIDI): Validation of a structured diagnostic clinical interview for impulse control disorders in an enriched community sample. Psychiatry Research, 265, 279-283 https://doi.org/10.1016/j.psychres.2018.05.006.

16. Christenson, G. A., Faber, R. J., de Zwaan, M., Raymond, N. C., Specker, S. M. Ekern, M. D., et al. (1994). Compulsive buying: Descriptive characteristics and psychiatric comorbidity. The Journal of Clinical Psychiatry, 55(1), 5-11 Retrieved from http://www.ncbi.nlm.nih.gov/pubmed/8294395.

17. Cormier, F., Muellner, J., \& Corvol, J.-C. (2013). Genetics of impulse control disorders in Parkinson's disease. Journal of Neural Transmission, 120(4), 665$671 \mathrm{https} / / /$ doi.org/10.1007/s00702-012-0934-4.

18. Corvol, J.-C., Artaud, F., Cormier-Dequaire, F., Rascol, O., Durif, F. Derkinderen, P., et al. (2018). Longitudinal analysis of impulse control disorders in Parkinson disease. Neurology. https://doi.org/10.1212/WNL. 0000000000005816 https://doi.org/10.1212/WNL.0000000000005816.

19. Dagher, A., \& Robbins, T. W. (2009). Personality, addiction, dopamine: Insights from Parkinson's disease. Neuron, 61(4), 502-510 https://doi.org/10 1016/j.neuron.2009.01.031.

20. Delpont, B., Lhommée, E., Klinger, H., Schmitt, E., Bichon, A., Fraix, V., et al. (2017). Psychostimulant effect of dopaminergic treatment and addictions in Parkinson's disease. Movement Disorders, 32(11), 1566-1573 https://doi.org/ 10.1002/mds.27101.

21. Eagle, D. M., \& Baunez, C. (2010). Is there an inhibitory-response-control system in the rat? Evidence from anatomical and pharmacological studies of behavioral inhibition. Neuroscience and Biobehavioral Reviews, 34, 50-72.

22. Elsworth, J. D., \& Roth, R. H. (1997). Dopamine synthesis, uptake, metabolism, and receptors: Relevance to gene therapy of Parkinson's disease. Experimental Neurology, 144, 4-9.

23. Engelmann, J. B., \& Brooks, A. M. (2009). Behavioral and neural effects of delays during intertemporal choice are independent of probability. Journal of Neuroscience, 29, 6055-6057.

24. Eppinger, B., Heekeren, H. R., \& Li, S. C. (2018). Age differences in the neural mechanisms of intertemporal choice under subjective decision conflict. Cerebral Cortex, 28, 3764-3774.

25. Eusebio, A., Witjas, T., Cohen, J., Fluchère, F., Jouve, E., Régis, J., \& Azulay, J. P. (2013). Subthalamic nucleus stimulation and compulsive use of dopaminergic medication in Parkinson's disease. Journal of Neurology, Neurosurgery and Psychiatry, 84(8), 868-874 https://doi.org/10.1136/jnnp-2012-302387.

26. Fernandez, H. H., \& Friedman, J. H. (1999). Punding on L-dopa. Movement Disorders, 14(5), 836-838.
27. Fowler, J. S., Volkow, N. D., Logan, J., Alexoff, D., Telang, F., Wang, G. J., Wong, C., Ma, Y., Kriplani, A., Pradhan, K., Schlyer, D., Jayne, M., Hubbard, B., Carter, P., Warner, D., King, P., Shea, C., Xu, Y., Muench, L., \& Apelskog, K. (2008). Fast uptake and long-lasting binding of methamphetamine in the human brain: Comparison with cocaine. Neuroimage, 43, 756-763.

28. Frederick, S., Loewenstein, G., \& O'Donoghue, T. (2003). In G. Loewenstein, D. Read, \& R. Baumeister (Eds.), Time discounting and time preference: A critical review (pp. 13-86). New York: Sage.

29. Garcia-Ruiz, J. P., Martinez Castrillo, J. C., Alonso-Canovas, A., Herranz Barcenas, A., Vela, L., Sanchez Alonso, P., Mata, M., Olmedilla Gonzales, N., \& Mahillo Fernandez, I. (2014). Impulse control disorder in patients with Parkinson's disease under dopamine agonist therapy: a multicentre study. Journal of Neurology, Neurosurgery and Psychiatry, 85(8), 840-844.

30. Giovannoni, G., O'Sullivan, J. D., Turner, K., Manson, A. J., \& Lees, A. J. (2000). Hedonistic homeostatic dysregulation in patients with Parkinson's disease on dopamine replacement therapies. Journal of Neurology, Neurosurgery, and Psychiatry, 68(4), 423-428 Retrieved from http://www.ncbi.nlm.nih.gov/ pubmed/10727476.

31. Goldstein, D. S., Sullivan, P., Holmes, C., Kopin, I. J., Basile, M. J., \& Mash, D. C. (2011). Catechols in post-mortem brain of patients with Parkinson disease. European Journal of Neurology, 18, 703-710.

32. Grace, A. A., Floresco, S. B., Goto, Y., \& Lodge, D. J. (2007). Regulation of firing of dopaminergic neurons and control of goal-directed behaviors. Trends in Neurosciences, 30, 220-227.

33. Grall-Bronnec, M., Victorri-Vigneau, C., Donnio, Y., Leboucher, J., Rousselet, M., Thiabaud, E., et al. (2018). Dopamine agonists and impulse control disorders: A complex association. Drug Safety, 41 https:/doi.org/10.1007/s40264-017-0590-6.

34. Hikosaka, O., Kim, H. F., Yasuda, M., \& Yamamoto, S. (2014). Basal ganglia circuits for reward value-guided behavior. Annual Review of Neuroscience, 37, 289-306.

35. Hill, P. F., Yi, R., Spreng, R. N., \& Diana, R. A. (2017). Neural congruence between intertemporal and interpersonal self-control: Evidence from delay and social discounting. Neuroimage, 162, 186-198.

36. Hu, H. (2016). Reward and aversion. Annual Review of Neuroscience, 39, 297-324.

37. Kable, J. W., \& Glimcher, P. W. (2007). The neural correlates of subjective value during intertemporal choice. Nature Neuroscience, 10, 1625-1633.

38. Kareken, D. A. (2018). Missing motoric manipulations: Rethinking the imaging of the ventral striatum and dopamine in human reward. Brain Imaging and Behavior. https://doi.org/10.1007/s11682-017-9822-8.

39. Kehagia, A. A., Housden, C. R., Regenthal, R., Barker, R. A., Müller, U., Rowe, J., Sahakian, B. J., \& Robbins, T. W. (2014). Targeting impulsivity in Parkinson's disease using atomoxetine. Brain, 137, 1986-1997.

40. Kelley, A. E. (2004). Memory and addiction: Shared neural circuitry and molecular mechanisms. Neuron, 44, 161-179.

41. Kirby, K. N., Petry, N. M., \& Bickel, W. K. (1999). Heroin addicts have higher discount rates for delayed rewards than non-drug-using controls. Journal of Experimental Psychology-General, 128, 78-87.

42. Knutson, B., \& Gibbs, S. E. B. (2007). Linking nucleus accumbens dopamine and blood oxygenation. Psychopharmacology, 191, 813-822.

43. Koran, L., Faber, R., \& Aboujaoude, E. (2006). Estimated prevalence of compulsive buying behavior in the United States. American Journal Of, (October), 18-21. Retrieved from http://ajp.psychiatryonline.org/doi/abs/10. 1176/ajp.2006.163.10.1806.

44. Kraemmer, J., Smith, K., Weintraub, D., Guillemot, V., Nalls, M. A., CormierDequaire, F., et al. (2016a). Clinical-genetic model predicts incident impulse control disorders in Parkinson's disease. Journal of Neurology, Neurosurgery and Psychiatry, 87(10), 1106-1111 https://doi.org/10.1136/jnnp-2015-312848.

45. Krämer, U. M., Cunillera, T., Càmara, E., Marco-Pallarés, J., Cucurell, D., Nager, W., Bauer, P., Schüle, R., Schöls, L., Rodriguez-Fornells, A., \& Münte, T. F. (2007). The impact of catechol-O-methyltransferase and dopamine D4 receptor genotypes on neurophysiological markers of performance monitoring. The Journal of Neuroscience, 27, 14190-14198.

46. Lamberti, V. M. J., Pereira, B., Lhommée, E., Bichon, A., Schmitt, E., Pelissier, P., et al. (2016). Profile of neuropsychiatric symptoms in Parkinson's disease: Surgical candidates compared to controls. Journal of Parkinson's Disease, 6(1), 133-142 https://doi.org/10.3233/JPD-150698.

47. Lawrence, A. D., Evans, A. H., \& Lees, A. J. (2003). Reviews compulsive use of dopamine replacement therapy in Parkinson 's disease : Reward systems gone awry ? The Lancet Neurology, 2(0), 595-604.

48. Lee, J. Y., Jeon, B. S., Kim, H. J., \& Park, S. S. (2012). Genetic variant of HTR2A associates with risk of impulse control and repetitive behaviors in Parkinson's disease. Parkinsonism \& Related Disorders, 18, 76-78. 
49. Lee, J. Y., Lee, E. K., Park, S. S., Lim, J. Y., Kim, H. J., Kim, J. S., \& Jeon, B. S. (2009). Association of DRD3 and GRIN2B with impulse control and related behaviors in Parkinson's disease. Movement Disorders, 24, 1803-1810.

50. Lhommée, E., Batir, A., Quesada, J.-L., Ardouin, C., Fraix, V., Seigneuret, E., et al. (2014). Dopamine and the biology of creativity: Lessons from Parkinson's disease. Frontiers in Neurology, 5 https://doi.org/10.3389/fneur. 2014.00055

51. Lhommée, E., Boyer, F., Wack, M., Pélissier, P., Klinger, H., Schmitt, E., et al. (2017). Personality, dopamine, and Parkinson's disease: Insights from subthalamic stimulation. Movement Disorders, 32(8), 1191-1200 https://doi. org/10.1002/mds.27065.

52. Lhommée, E., Klinger, H., Thobois, S., Schmitt, E., Ardouin, C., Bichon, A., et al. (2012). Subthalamic stimulation in Parkinson's disease: Restoring the balance of motivated behaviours. Brain, 135(5), 1463-1477 https://doi.org/10.1093/ brain/aws078.

53. Lhommée, E., Wojtecki, L., Czernecki, V., Witt, K., Maier, F., Tonder, L., et al. (2018). Behavioural outcomes of subthalamic stimulation and medical therapy versus medical therapy alone for Parkinson's disease with early motor complications (EARLYSTIM trial): Secondary analysis of an open-label randomised trial. The Lancet Neurology, 17(3), 223-231 https://doi.org/10. 1016/S1474-4422(18)30035-8.

54. Maillet, A., Krack, P., Lhommée, E., Météreau, E., Klinger, H., Favre, E., et al. (2016). The prominent role of serotonergic degeneration in apathy, anxiety and depression in de novo Parkinson's disease. Brain, 139(9), 2486-2502 https://doi.org/10.1093/brain/aww162.

55. Marco-Pallares, J., Mohammadi, B., Samii, A., \& Münte, T. F. (2010). Brain activations reflect individual discount rates in intertemporal choice. Brain Research, 1320, 123-129.

56. Martínez-Fernández, R., Schmitt, E., Martinez-Martin, P., \& Krack, P. (2016). The hidden sister of motor fluctuations in Parkinson's disease: A review on nonmotor fluctuations. Movement Disorders, 31(8), 1080-1094 https://doi. org/10.1002/mds.26731.

57. Mazur, J. E. (1984). Tests of an equivalence rule for fixed and variable reinforcer delays. Journal of Experimental Psychology. Animal Behavior Processes, 10, 426-436.

58. McClure, S. M., Ericson, K. M., Laibson, D. I., Loewenstein, G., \& Cohen, J. D. (2007). Time discounting for primary rewards. The Journal of Neuroscience, 27, 5796-5804.

59. McClure, S. M., Laibson, D. I., Loewenstein, G., \& Cohen, J. D. (2004). Separate neural systems value immediate and delayed monetary rewards. Science, 306, 503-507

60. Milenkova, M., Mohammadi, B., Kollewe, K., Schrader, C., Fellbrich, A., Wittfoth, M., Dengler, R., \& Münte, T. F. (2011). Intertemporal choice in Parkinson's disease. Movement Disorders, 26, 2004-2010.

61. Mouaffak, F., Leite, C., Hamzaoui, S., Benyamina, A., Laqueille, X., \& Kebir, O. (2017). Naltrexone in the treatment of broadly defined behavioral addictions: A review and meta-analysis of randomized controlled trials. European Addiction Research, 23, 204-210.

62. Nakum, S., \& Cavanna, A. E. (2016). The prevalence and clinical characteristics of hypersexuality in patients with Parkinson's disease following dopaminergic therapy: A systematic literature review. Parkinsonism \& Related Disorders, 25, 10-16 https://doi.org/10.1016/j.parkreldis.2016.02.017.

63. Nirenberg, M. J., \& Waters, C. (2006). Compulsive eating and weight gain related to dopamine agonist use. Movement Disorders, 21(4), 524-529 https://doi.org/10.1002/mds.20757.

64. O'Sullivan, S. S., Djamshidian, A., Evans, A. H., Loane, C. M., Lees, A. J., \& Lawrence, A. D. (2010). Excessive hoarding in Parkinson's disease. Movement Disorders, 25(8), 1026-1033 https://doi.org/10.1002/mds.23016.

65. Okai, D., Askey-Jones, S., Samuel, M., O'Sullivan, S. S., Chaudhuri, K. R., Martin, A., et al. (2013). Trial of CBT for impulse control behaviors affecting Parkinson patients and their caregivers. Neurology, 80, 792-799.

66. Pagonabarraga, J., Kulisevsky, J., Strafella, A. P., \& Krack, P. (2015). Apathy in Parkinson's disease: Clinical features, neural substrates, diagnosis, and treatment. The Lanc Neurology, 14(5), 518-531 https://doi.org/10.1016/ S1474-4422(15)00019-8.

67. Papay, K., Xie, S. X., Stern, M., Hurtig, H., Siderowf, A., Duda, J. E., Minger, J., \& Weintraub, D. (2014). Naltrexone for impulse control disorders in Parkinson disease: a placebo-controlled study. Neurology, 83, 826-833.

68. Peters, J., \& Büchel, C. (2009). Overlapping and distinct neural systems code for subjective value during intertemporal and risky decision making. Journal of Neuroscience, 29, 15727-15734.
69. Phu, A. L., Xu, Z., Brakoulias, V., Mahant, N., Fung, V. S. C., De Moore, G., et al. (2014). Effect of impulse control disorders on disability and quality of life in Parkinson's disease patients. Journal of Clinical Neuroscience: Official Journal of the Neurosurgical Society of Australasia, 21(1), 63-66 https://doi.org/10.1016/j.jocn.2013.02.032.

70. Picconi, B., Hernández, L. F., Obeso, J. A., \& Calabresi, P. (2017). Motor complications in Parkinson's disease: Striatal molecular and electrophysiological mechanisms of dyskinesias. Movement Disorders, 00(00), 1-10 https://doi.org/10.1002/mds.27261.

71. Postuma, R. B., Berg, D., Stern, M., Poewe, W., Olanow, C. W., Oertel, W., et al. (2015). MDS clinical diagnostic criteria for Parkinson's disease. Movement Disorders, 30(12), 1591-1601 https://doi.org/10.1002/mds.26424.

72. Rabinak, C. A., \& Nirenberg, M. J. (2010). Dopamine agonist withdrawal syndrome in Parkinson disease. Archives of Neurology, 67(1), 58-63 https:// doi.org/10.1001/archneurol.2009.294.

73. Rae, C. L., Nombela, C., Rodríguez, P. V., Ye, Z., Hughes, L. E., Jones, P. S., Ham, T., Rittman, T., Coyle-Gilchrist, I., Regenthal, R., Sahakian, B. J., Barker, R. A., Robbins, T. W., \& Rowe, J. B. (2016). Atomoxetine restores the response inhibition network in Parkinson's disease. Brain, 139, 2235-2248.

74. Riba, J., Kramer, U. M., Heldmann, M., Richter, S., \& Münte, T. F. (2008). Dopamine agonist increases risk taking but blunts reward-related brain activity. PLoS One, 3, e2479.

75. Rieu, I., Martinez-Martin, P., Pereira, B., De Chazeron, I., Verhagen Metman, L., Jahanshahi, M., et al. (2015). International validation of a behavioral scale in Parkinson's disease without dementia. Movement Disorders, 30(5), 705-713 https://doi.org/10.1002/mds.26223.

76. Rotondo, A., Bosco, D., Plastino, M., Consoli, A., \& Bosco, F. (2010). Clozapine for medication-related pathological gambling in Parkinson disease. Movement Disorders, 25(12), 1994-1995.

77. Samuel, M., Rodriguez-Oroz, M., Antonini, A., Brotchie, J. M., Ray Chaudhuri, K., Brown, R. G., et al. (2015). Management of impulse control disorders in Parkinson's disease: Controversies and future approaches. Movement Disorders, 30(2), 150-159 https://doi.org/10.1002/ mds.26099.

78. Schmitt, E., Krack, P., Castrioto, A., Klinger, H., Bichon, A., Lhommée, E., et al. (2018). The neuropsychiatric fluctuations scale for Parkinson's disease: A pilot study. Movement Disorders Clinical Practice, 5(3), 265-272 https://doi. org/10.1002/mdc3.12607.

79. Schott, B. H., Minuzzi, L., Krebs, R. M., Elmenhorst, D., Lang, M., Winz, O. H., Seidenbecher, C. I., Coenen, H. H., Heinze, H. J., Zilles, K., Duzel, E., \& Bauer, A. (2008). Mesolimbic functional magnetic resonance imaging activations during reward anticipation correlate with reward-related ventral striatal dopamine release. The Journal of Neuroscience, 28, 14311-14319.

80. Schrag, A., Horsfall, L., Walters, K., Noyce, A., \& Petersen, I. (2015). Prediagnostic presentations of Parkinson's disease in primary care: A casecontrol study. The Lancet Neurology, 14(1), 57-64 https://doi.org/10.1016/ S1474-4422(14)70287-X.

81. Sierra, M., Carnicella, S., Strafella, A. P., Bichon, A., Lhommée, E., Castrioto, A., et al. (2015). Apathy and impulse control disorders: Yin \& yang of dopamine dependent behaviors. Journal of Parkinson's Disease, 5(3), 625-636.

82. Smith, K. M., Xie, S. X., \& Weintraub, D. (2016). Impulse control disorders symptoms and dopamine transporter imaging in Parkinson disease. Journal of Neurology, Neurosurgery and Psychiatry, 87(8), 864-870.

83. Solla, P., Bortolato, M., Cannas, A., Mulas, C. S., \& Marrosu, F. (2015). Paraphilias and paraphilic disorders in Parkinson's disease: A systematic review of the literature. Movement Disorders, 30(5), 604-613 https://doi.org/ 10.1002/mds.26157.

84. Stark, A. J., Smith, C. T., Lin, Y. C., Petersen, K. J., Trujillo, P., van Wouwe, N. C., Kang, H., Donahue, M. J., Kessler, R. M., Zald, D. H., \& Claassen, D. O. (2018). Nigrostriatal and mesolimbic D(2/3) receptor expression in Parkinson's disease patients with compulsive reward-driven behaviors. The Journal of Neuroscience, 38, 3230-3239.

85. Szamosi, A., Nagy, H., \& Kéri, S. (2013). Delay discounting of reward and caudate nucleus volume in individuals with a-synuclein gene duplication before and after the development of Parkinson's disease. Neurodegenerative Diseases, 11, 72-78.

86. Thobois, S., Ardouin, C., Lhommée, E., Klinger, H., Lagrange, C., Xie, J., et al. (2010). Non-motor dopamine withdrawal syndrome after surgery for Parkinson's disease: Predictors and underlying mesolimbic denervation. Brain, 133(4), 1111-1127 https://doi.org/10.1093/brain/awq032. 
87. Thomas, A., Bonanni, L., Gambi, F., DI lorio, A., \& Onofrj, M. (2010). Pathological gambling in Parkinson disease is reduced by amantadine. Annals of Neurology, 68(3), 400-404.

88. Todes, C. J., \& Lees, A. J. (1985). Occasional review the pre-morbid personality of patients with Parkinson 's disease. Brain, 97-100.

89. Todorova, A., Samuel, M., Brown, R. G., \& Chaudhuri, K. R. (2015). Infusion therapies and development of impulse control disorders in advanced Parkinson disease: Clinical experience after 3 years' follow-up. Clinical Neuropharmacology, 38(4), 132-134

90. Vallelunga, A., Flaibani, R., Formento-Dojot, P., Biundo, R., Facchini, S., \& Antonini, A. (2012). Role of genetic polymorphisms of the dopaminergic system in Parkinson's disease patients with impulse control disorders. Parkinsonism \& Related Disorders, 18, 397-399.

91. van Eimeren, T., Pellecchia, G., Cilia, R., Ballanger, B., Steeves, T. D., Houle, S., Miyasaki, J. M., Zurowski, M., Lang, A. E., \& Strafella, A. P. (2010). Druginduced deactivation of inhibitory networks predicts pathological gambling in PD. Neurology, 75, 1711-1716.

92. Vazey, E. M., \& Aston-Jones, G. (2012). The emerging role of norepinephrine in cognitive dysfunctions of Parkinson's disease. Frontiers in Behavioral Neuroscience, 6, 48.

93. Volkow, N. D., \& Baler, R. D. (2015). NOW vs LATER brain circuits: Implications for obesity and addiction. Trends in Neurosciences, 38, 345-352.

94. Volkow, N. D., Tomasi, D., Wang, G. J., Logan, J., Alexoff, D. L., Jayne, M., Fowler, J. S., Wong, C., Yin, P., \& Du, C. (2014). Stimulant-induced dopamine increases are markedly blunted in active cocaine abusers. Molecular Psychiatry, 19, 1037-1043.

95. Voon, V., Mehta, A. R., \& Hallett, M. (2011a). Impulse control disorders in Parkinson's disease. Current Opinion in Neurology, 24(4), 324-330 https://doi. org/10.1097/WCO.0b013e3283489687

96. Voon, V., Reynolds, B., Brezing, C., Gallea, C., Skaljic, M., Ekanayake, V., Fernandez, H., Potenza, M. N., Dolan, R. J., \& Hallett, M. (2010). Impulsive choice and response in dopamine agonist-related impulse control behaviors. Psychopharmacology, 207, 645-659.

97. Voon, V., Sohr, M., Lang, A. E., Potenza, M. N., Siderowf, A. D., Whetteckey, J., et al. (2011b). Impulse control disorders in parkinson disease: A multicenter case-control study. Annals of Neurology, 69(6), 986-996 https://doi.org/10. 1002/ana.22356.

98. Warner, C. B., Ottman, A. A., \& Brown, J. N. (2018). The role of atomoxetine for Parkinson. Disease-Related Executive Dysfunction: A Systematic Review. J Clin Psychopharmacol, 38, 627-631.

99. Weintraub, D., \& Burn, D. J. (2011). Parkinson's disease: The quintessential neuropsychiatric disorder. Movement Disorders, 26(6), 1022-1031 https://doi. org/10.1002/mds.23664.

100. Weintraub, D., David, A. S., Evans, A. H., Grant, J. E., \& Stacy, M. (2015). Clinical spectrum of impulse control disorders in Parkinson's disease. Movement Disorders, 30(2), 121-127 https://doi.org/10.1002/mds.26016.

101. Weintraub, D., Hoops, S., Shea, J. A., Lyons, K. E., Pahwa, R., Driver-Dunckley, E. D., et al. (2009). Validation of the questionnaire for impulsive-compulsive disorders in Parkinson's disease. Movement Disorders, 24(10), 1461-1467 https://doi.org/10.1002/mds.22571.

102. Weintraub, D., Koester, J., Potenza, M. N., Siderowf, A. D., Stacy, M., Voon, V., et al. (2010). Impulse control disorders in Parkinson disease: a cross-sectional study of 3090 patients. Archives of Neurology, 67(5), 589-595 https://doi.org/ 10.1001/archneurol.2010.65

103. Weintraub, D., Mamikonyan, E., Papay, K., Shea, J. A., Xie, S. X., \& Siderowf, A. (2012). Questionnaire for impulsive-compulsive disorders in Parkinson's disease-rating scale. Movement Disorders, 27(2), 242-247 https://doi.org/10. 1002/mds.24023.

104. Weintraub, D., Papay, K., Siderowf, A., \& Markers, P. P. (2013). Screening for impulse control symptoms in patients with de novo Parkinson disease: A case control study. Neurology, 80(2), 176-180 https://doi.org/10.1212/WNL. ob013e31827b915c.

105. Ye, Z., Altena, E., Nombela, C., Housden, C. R., Maxwell, H., Rittman, T., Huddleston, C., Rae, C. L., Regenthal, R., Sahakian, B. J., Barker, R. A., Robbins, T. W., \& Rowe, J. B. (2015). Improving response inhibition in Parkinson's disease with atomoxetine. Biological Psychiatry, 77, 740-748.

106. Ye, Z., Hammer, A., Camara, E., \& Münte, T. F. (2011). Pramipexole modulates the neural network of reward anticipation. Human Brain Mapping, 32, 800-811.

107. Ye, Z., Rae, C. L., Nombela, C., Ham, T., Rittman, T., Jones, P. S., Rodríguez, P. V., Coyle-Gilchrist, I., Regenthal, R., Altena, E., Housden, C. R., Maxwell, H., Sahakian, B. J., Barker, R. A., Robbins, T. W., \& Rowe, J. B. (2016). Predicting beneficial effects of atomoxetine and citalopram on response inhibition in Parkinson's disease with clinical and neuroimaging measures. Human Brain Mapping, 37, 1026-1037.

108. Zainal Abidin, S., Tan, E. L., Chan, S. C., Jaafar, A., Lee, A. X., Abd Hamid, M. H., Abdul Murad, N. A., Pakarul Razy, N. F., Azmin, S., Ahmad Annuar, A., Lim, S. Y., Cheah, P. S., Ling, K. H., \& Mohamed Ibrahim, N. (2015). DRD and GRIN2B polymorphisms and their association with the development of impulse control behaviour among Malaysian Parkinson's disease patients. BMC Neurology, 15, 59.

109. Zhang, Y. Y., Xu, L., Liang, Z. Y., Wang, K., Hou, B., Zhou, Y., Li, S., \& Jiang, T. (2018). Separate neural networks for gains and losses in intertemporal choice. Neuroscience Bulletin, 34, 725-735.

\section{Ready to submit your research? Choose BMC and benefit from:}

- fast, convenient online submission

- thorough peer review by experienced researchers in your field

- rapid publication on acceptance

- support for research data, including large and complex data types

- gold Open Access which fosters wider collaboration and increased citations

- maximum visibility for your research: over $100 \mathrm{M}$ website views per year

At BMC, research is always in progress.

Learn more biomedcentral.com/submissions 